\title{
REPORT ON THE 11th INTERNATIONAL AFIR COLLOQUIUM 2001
}

The 11th International AFIR Colloquium was held in Toronto, Canada, on 5 to 7 September 2001.

Proceedings started off with an informal, welcome reception at the conference hotel giving everyone the opportunity to renew old acquaintances and meet new faces. The highlight of the social programme was a reception and dinner in the wonderful Art Gallery of Ontario. Delegates had the opportunity to wander round the galleries which contained a wonderful variety of exhibits. This was followed by an excellent dinner accompanied by a string quartet playing mainly a North American selection.

The format of the lunches on the conference days was an innovation for AFIR as these included guest speakers Sherry Cooper and Malcolm Knight. The two presentations were very different but both gave delegates valuable insights into North American and World economics.

The main conference proceedings were started off by Josephine Marks (Chair of the organising committee), Harry Panjer (Chair of the scientific committee) and Jean Berthon (Chairman of AFIR). Jean Berthon praised the continued high quality of the papers but called for greater numbers of collaborative papers which bring together academics and practitioners. He saw this as vital for the continued good health of the AFIR colloquia.

There were two guest speakers. Dr Michel Crouhy gave a wide ranging and informative talk on the new Basel Capital Accord and its interaction with risk management. Professor Paul Embrechts discussed recent developments on the assessment of Value at Risk for dependent risks.

The conference attracted 33 contributed papers on a wide range of topics: investment-linked assurance; pricing theory; pensions and annuities; investment risk management; fair value; derivative pricing; and portfolio management. The authors all have to be complimented for the high quality of the papers themselves and also for the high quality of their presentations.

The 2002 colloquium will be held concurrently with the International Congress of Actuaries in Cancun, Mexico from 17 to 22 March, 2002.

Andrew Cairns

\section{Conference Papers}

The books containing the papers that were presented at the 11th Annual International AFIR Colloquium are now available for purchase. If you are interested in purchasing the two volumes, please contact Judy Findlay at the Canadian Institute of Actuaries Secretariat by e-mail, by phone at (613) 236-8196 ext. 114 or by fax at (613) 233-4552.

Price: $\$ 100 \mathrm{CDN}$ (including shipping/handling and taxes).

QUANTITIES ARE LIMITED 